\title{
Use of saturation diving technique for tunnel boring machine cutterhead intervention in the Tuen Mun-Chek Lap Kok Link Sub-sea Tunnel Project, Hong Kong
}

\author{
A W Y Chan ${ }^{1}$, Charles H C Yeung ${ }^{2}$, A J Westmoreland ${ }^{2}$, S W Fok ${ }^{2}$, Conrad C W Ng ${ }^{2}$ and F Guedon \\ ${ }^{1}$ Highways Department, the HKSAR Government, Hong Kong, People's Republic of China \\ ${ }^{2}$ AECOM Asia Company Limited, Hong Kong, People's Republic of China \\ ${ }^{3}$ Dragages-Bouygues JV, Dragages Hong Kong Limited, Hong Kong, People's Republic of China
}

\begin{abstract}
The entire Tuen Mun-Chek Lap Kok Link (TM-CLKL) was commissioned on 27 December 2020 and it comprises a 9km-long dual 2-lane carriageway between Tuen Mun and North Lantau, Hong Kong. Construction of the 5km-long subsea tunnels was carried out by two $14 \mathrm{~m}$ diameter Tunnel Boring Machines (TBMs). The tunnel alignment for the TMCLKL sub-sea tunnel section is in mixed ground condition with the first $500 \mathrm{~m}$ in mixed geology of slightly to moderately decomposed granite and completely decomposed granite (CDG), followed by soft ground condition with CDG, alluvial sand, alluvial clay and marine deposit. This mixed ground geology requires regular TBM cutterhead interventions to change the worn-out cutting tools during the tunnelling operation. As the tunnel alignment is up to $55 \mathrm{~m}$ below the sea level with the deepest seabed level at $-21 \mathrm{mPD}$, in order to maintain the cutting face stability during the intervention, the intervention pressure could be up to 6 bars. This paper describes different techniques used for TBM interventions under the sea such as trimix bounce mode and saturation mode that appears first time in Hong Kong under a high hyperbaric pressure to change the worn-out cutting tools at the TBM cutterhead.
\end{abstract}

KEYWORDS Civil Engineering; Geotechnical Engineering; Tunnelling; Saturation Diving; TBM Intervention CONTACT Charles HC Yeung sret2cyg@trunkroadt2.com Received 21 October 2019

\section{Introduction}

The entire Tuen Mun-Chek Lap Kok Link (TMCLKL) was commissioned on 27 December 2020 and it comprises a $9 \mathrm{~km}$ long dual 2-lane carriageway between Tuen Mun and North Lantau, Hong Kong (Figure 1). The alignment commences at the Lung Mun Road and Lung Fu Road Roundabout in Tuen Mun Area 46. It heads southeast on an elevated structure over Lung Mun Road and lands on a new reclamation (referred to as the Northern Landfall (NLF)) adjacent to the Tuen Mun River Trade Terminal (RTT). The alignment turns south and heads into a $5 \mathrm{~km}$ long sub-sea tunnel passing under a busy navigation channel between Lantau Island and Tuen Mun - the Urmston Road. After crossing the Urmston Road, the alignment daylights at the eastern edge of the reclaimed Hong Kong-Zhuhai-Macao Bridge, Hong Kong Port (HZMB HK Port) near Hong Kong International Airport at Chek Lap Kok (referred to as the Southern Landfall (SLF)) and then head eastwards on a marine viaduct to connect the North Lantau Highway at Tai Ho Wan of Lantau.

Construction of the sub-sea tunnels across the Urmston Road between the HZMB HK Port and Tuen Mun was carried out by two $14 \mathrm{~m}$ diameter Tunnel Boring Machines (TBMs). The adoption of TBM completely avoided the impact on the busy Urmston Road during construction and minimised the impacts on the marine habitat of the Chinese White Dolphin, within and near the works site of the project.

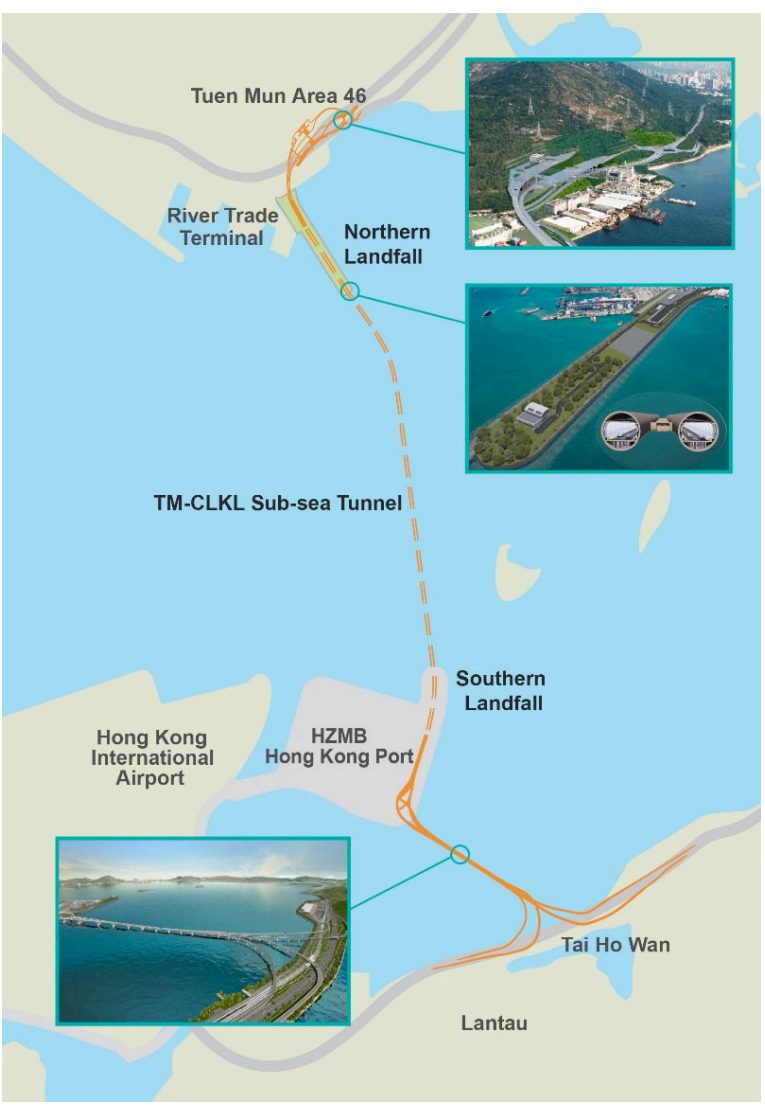

Figure 1. General view of TM-CLKL alignment. 
This paper describes the different techniques used for TBM interventions under the sea to change the worn-out cutting tools at the TBM cutterhead.

\section{TBM cutterhead intervention strategy during project design stage}

The designed tunnel alignment for the TM-CLKL sub-sea tunnel section was in mixed ground condition with the first 500m in mixed geology of slightly to moderately decomposed granite and completely decomposed granite (CDG), followed by soft ground condition with CDG, alluvial sand, alluvial clay and marine deposit (Figure 2). With this mixed ground geology, the TBM disc cutters and cutting tools were subjected to wear and tear. The maintenance of the TBM cutterhead required regular inspections to monitor cutter tool wear, replace worn tools and undertake any repairs necessary to the cutterhead itself, in order to prevent the TBM from becoming stuck underground. The process of deploying workers under pressure to the TBM excavation chamber to inspect the TBM cutterhead and replace the worn-out cutters or cutting tools is commonly called TBM cutterhead interventions. During these manned interventions, compressed air was used to balance the hydrostatic and earth pressures, creating a hyperbaric environment within the excavation chamber of the TBM. Failure to balance the groundwater pressure would lead to face instability due to the flow of water from the ground into the TBM excavation chamber. Water flow from the face might result in ground material being carried into the excavation chamber during compressed air works, causing face collapse, with a subsequent ground surface settlement or, in more serious incidents, a sinkhole at the ground surface above the TBM.

As the tunnel alignment is up to $55 \mathrm{~m}$ below the sea level with the deepest seabed level at $-21 \mathrm{mPD}$, in order to maintain the cutting face stability during each intervention, the intervention pressure could be up to 6 bars.

Under such a high pressure, the compressed air workers could not stay for a long time and work efficiently to carry out TBM cutterhead interventions because, under this pressure, workers breathing air would likely to have the narcosis effect due to high concentration of nitrogen and that the high concentration of oxygen would also cause oxygen toxicity. In addition, according to the decompression table that had to be approved by the authority prior to use, after the workers are exposed under this high pressure for about 1.5 hours of work, they have to decompress for about 2.5 hours back to atmospheric pressure and take a rest. As it normally takes an hour to replace a worn-out cutter, for a TBM having more than 100 disc cutters, the use of traditional intervention technique for TBM cutterhead interventions will be impractical if not impossible.

Workers working in a compressed air environment under such a high pressure will be exposed to Occupation Safety and Health (OSH) risk due to the narcosis effects
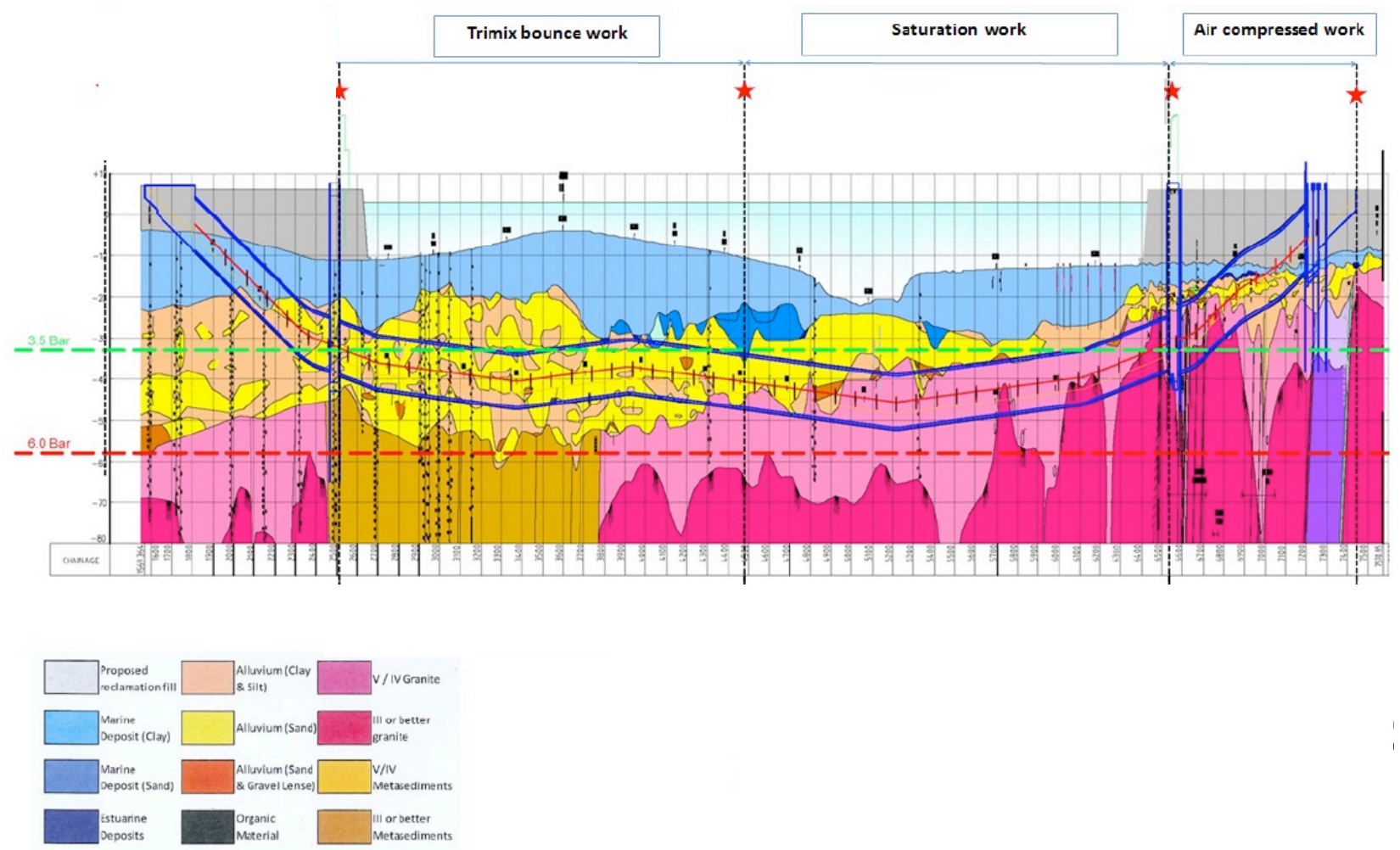

Figure 2. Geological profile of the TM-CLKL sub-sea tunnels and different modes of hyperbaric works along the alignment. 
and high dosage of oxygen. In addition, the risk of having decompression illness (DCI) is high due to frequent compression and decompression at the start and end of each intervention. In order to minimise the OSH and DCI risk for the compressed air workers, the project consultant, AECOM, has introduced the concept of saturation diving technique as the TBM cutterhead intervention strategy during the project design stage. AECOM has put down the provisions of the saturation diving technique in the Employer's Requirements of the Contract which require the Contractor to provide the saturation diving equipment and facilities and design the TBM to allow the use of saturation diving technique for TBM cutterhead interventions if needed. The use of saturation diving technique for TBM cutterhead interventions had previously been deployed by only a few tunnel projects around the world and was the first time in Hong Kong. Figure 3 shows the recommended pressure range for different modes of interventions.

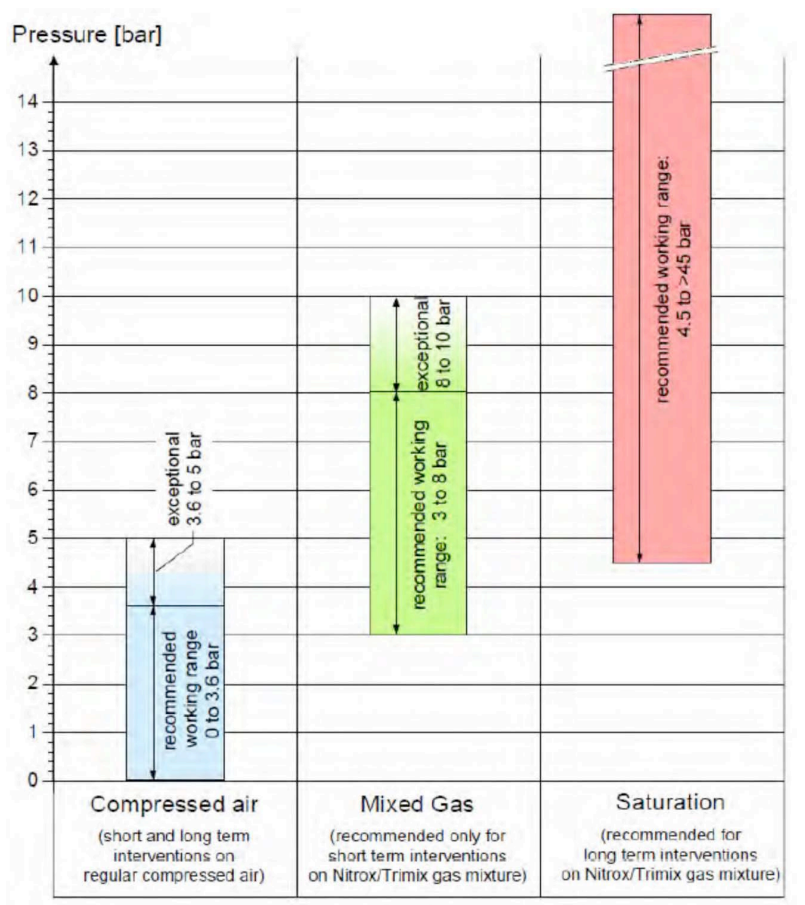

Figure 3. Pressure range for compressed air, mixed gas and saturation interventions.

Saturation diving is a technique which was first adopted for commercial use in 1965 by Westinghouse to replace faulty trash racks at $61 \mathrm{~m}$ on the Smith Mountain Dam in the United States (Kindwall, 1990). Since then, it was used in commercial offshore diving. Whenever there is maintenance or repairs required at the offshore infrastructures under the sea, deep-sea divers are deployed to dive at pressures of over 5 bars or more and stay underwater for a certain period of time to inspect and repair the parts. These deep-sea divers are "saturated". They breathe a mixture of gas instead of air to reduce the narcosis effect and minimise oxygen toxicity. The divers live inside a diving bell under the sea and can stay underwater to work for a month without the need for daily decompression.

When the saturation diving technique is used in the tunnelling industry for TBM cutterhead interventions, the workers are saturated. They work inside the TBM excavation chamber under compressed air but breathe mixed gas via an umbilical hose. After they work in a hyperbaric environment for a few hours, they will be back to a hyperbaric chamber to take a rest but are always under pressure. These saturated workers can stay and work continuously in a hyperbaric environment for a month before they need to be decompressed back to atmospheric pressure.

\section{Statutory approval process}

According to the CAP59M Factories and Industrial Undertakings (Work in Compressed Air) Regulations of the HKSAR, no person shall be employed in compressed air at a pressure exceeding 3.45 bars without permission from the Commissioner. In this connection, exemption from the Labour Department was required to carry out hyperbaric works above 3.45 bars. Since the saturation diving technique for TBM cutterhead interventions in TMCLKL sub-sea tunnels was the first time to be used in Hong Kong with no precedent, the process to obtain an exemption from the authority to use the saturation diving technique for TBM cutterhead interventions was a crucial task before the actual implementation of the saturation diving operation.

As soon as the contract was awarded in August 2013, the Contractor commenced understanding the requirements to get the exemption for the saturation hyperbaric works. Since there was neither local guideline nor code of practice for this kind of hyperbaric works in Hong Kong, the Contractor was required to plan the saturation hyperbaric works based on renowned international guidelines and practice and submit a proposal for the authority's review and consideration.

Based on the TM-CLKL tunnel alignment, the Contractor planned to deploy three modes of hyperbaric technique for TBM cutterhead interventions. These three modes of hyperbaric techniques were Air Mode (from 0 bar to 4.2 bars), Trimix Bounce Mode (from 3.45 bars to 5.5 bars) and Saturation Mode (from 3.45 bars to 6 bars) (Figure 2). Air Mode is the conventionally manned intervention practice in which the hyperbaric workers breathe normal air during each intervention. Decompression of the hyperbaric workers is required after a period of working time which varies according to the working pressure. At 4.2 bars, the allowable working time will be up to a maximum of 100 minutes followed by 147 minutes of decompression. Trimix Bounce Mode is similar to Air Mode except the hyperbaric workers breathe a trimix gas comprising oxygen, nitrogen and helium with a composition of $20 / 47 / 33\left(\mathrm{O}_{2} / \mathrm{N}_{2} / \mathrm{He}\right)$ 
instead of normal air via the umbilical hose. Decompression of the hyperbaric workers is also required after a period of working time which varies according to the working pressure. At 5.5 bars, the allowable working time will be up to a maximum of 90 minutes followed by 305 minutes of decompression. Under the Saturation Mode, the hyperbaric workers breathe trimix gas with a composition of 12/35/53 $\left(\mathrm{O}_{2} / \mathrm{N}_{2} / \mathrm{He}\right)$. They could stay and live under a trimix gas environment in a hyperbaric chamber for up to 28 days. The percentage of the oxygen, nitrogen and helium in the trimix gas will be adjusted depending on the working pressure and whether the hyperbaric workers are working inside the TBM cutterhead or living in the hyperbaric chamber. The workers were able to carry out TBM cutterhead interventions for 6 hours a day for 25 days with the last 3 days for decompression.

Since the saturation diving technique for TBM cutterhead interventions was being deployed for the first time in Hong Kong, there were no competent hyperbaric workers available in the local manpower market. All the hyperbaric workers had to be imported to Hong Kong by applying for working visas from the Immigration Department. In addition, there is no guideline in Hong Kong to regulate saturation works.

The Contractor therefore planned his saturation works for TBM cutterhead interventions with reference to several renowned international guidelines and compliance with relevant statutory requirements listed in table 1.

To apply for exemption from the Labour Department to carry out hyperbaric works for the TM-CLKL project, the Contractor prepared a comprehensive submission containing:

(1) a method statement for different modes of hyperbaric works deployed for the TBM cutterhead intervention;

(2) an Emergency Response Plan detailing the required coordinated actions among the Contractor and the Public Emergency Authorities (PEA) including the Fire Services Department, Hospital Authority, Hong Kong Police Force; and

(3) a Risk Assessment on the hyperbaric works.

Before getting the exemption to carry out saturation works in Hong Kong for the first time, there were critical issues to be resolved which are discussed in the following paragraphs.

An Appointed Medical Practitioner (AMP) was required for the hyperbaric works. However, there was no local AMP in Hong Kong with relevant experience in saturation diving. Therefore, in addition to a local AMP and his backup who were employed as required to take care of the health of the hyperbaric workers, AMP from overseas countries, with backup, had to be employed to oversee the saturation works of the project and supervise the local AMPs. These AMPs from overseas countries had to apply for a limited registration, renewable each year, from the Medical Council prior to practising in Hong Kong.

Other than the AMPs who were stated in the ITA guidelines, an additional trauma surgeon and his backup were also required to carry out emergency operations under a hyperbaric environment in the hyperbaric medical chamber in the event of any serious accidents that might happen during the TBM intervention works.

The decompression tables deployed for the trimix bounce mode and saturation mode were not statutory decompression tables. They were commercial decompression tables developed by the hyperbaric consultant. In order to safeguard the health of the hyperbaric workers using these commercial decompression tables for decompression, these decompression tables were required to be validated. A validation of the decompression tables using numerical models was therefore conducted by a physiological specialist, which was followed by a fullscale physical trial run of the trimix bounce decompression and saturation decompression with a team of hyperbaric

Table 1. Reference of International Guidelines/Statutory Requirements for saturation works.

\begin{tabular}{|c|l|l|}
\hline \multicolumn{1}{|c|}{ Subjects } & \multicolumn{1}{|c|}{ Guidelines / Statutory Requirements } \\
\hline 1 & Imported French Hyperbaric Workers & Hong Kong Labour Law and French Labour Law \\
\hline 2 & $\begin{array}{l}\text { Hyperbaric work process including airmode, } \\
\text { trimix bounce mode and saturation mode }\end{array}$ & $\begin{array}{l}\text { The International Tunnelling Association Working } \\
\text { Group (2015) }\end{array}$ \\
\hline 3 & $\begin{array}{l}\text { Qualifications of the hyperbaric workers, testing and } \\
\text { certification of the hyperbaric plant and equipment }\end{array}$ & $\begin{array}{l}\text { The International Marine Contractor Association } \\
\text { (IMCA) D 018 (2014) }\end{array}$ \\
\hline 5 & Medical equipment of saturation works & $\begin{array}{l}\text { The Diving Medical Advisory Committee (DMAC) } \\
\text { DMAC 15 revision 4 (2014) }\end{array}$ \\
\hline 6 & $\begin{array}{l}\text { Hygiene standard of the saturation diving hyperbaric } \\
\text { chamber }\end{array}$ & $\begin{array}{l}\text { The Diving Medical Advisory Committee DMAC 26 } \\
\text { (2016) }\end{array}$ \\
\hline 7 & $\begin{array}{l}\text { Requirements for accelerated emergency } \\
\text { decompression }\end{array}$ & $\begin{array}{l}\text { The Diving Medical Advisory Committee DMAC 28 } \\
\text { (2014) }\end{array}$ \\
\hline
\end{tabular}


workers witnessed by the Independent Hyperbaric Advisor appointed by the Highways Department.

Numerous meetings among the Labour Department, Fire Services Department, Hospital Authority, Hong Kong Police Force, the Client - the Highways Department, the Project Consultant - AECOM and the Contractor were organised for the Contractor to address comments from government authorities on the submission. Besides, emergency drills with the Fire Services Department, Hospital Authority and Hong Kong Police Force were held to streamline the emergency actions depicted in the Emergency Response Plan before the exemption from hyperbaric works over 3.45 bars was granted by the Commissioner for Labour to allow the Contractor to carry out the saturation diving operation for TBM cutterhead interventions.

\section{Implementation of saturation diving technique for TBM cutterhead interventions}

\subsection{Setup for saturation diving operation}

The Employer's Requirements for the project required the Contractor to provide saturation diving equipment and facilities and design the TBM to allow the use of the saturation diving technique for TBM cutterhead interventions if needed.

On site, an area near the tunnel portal was reserved for construction of a living habitat (Figure 4), a compound which housed the hyperbaric chambers including a living chamber where the saturation workers lived under pressure in a trimix gas environment; a medical chamber where medical treatment or surgical operations could be conducted under pressure, a wet pod equipped with shower and toilet facilities for use under pressure by the saturation workers, a decompression chamber where the saturation workers were able to stay for the 3-day decompression, and two Transfer Under Pressure (TUP) shuttles which were used to transport the saturation workers under pressure to the TBM for cutterhead interventions. These saturation workers were under round-the-clock surveillance by a team of technicians managed by an experienced Hyperbaric Operation Supervisor via a centralised control panel and gas panel where the storage pressure, storage temperature and trimix gas content were monitored (Figure 5).

A Dangerous Goods store was also constructed in the close vicinity to the living habitat for trimix gas storage. The whole compound was equipped with fire-fighting installations approved by the Fire Services Department.

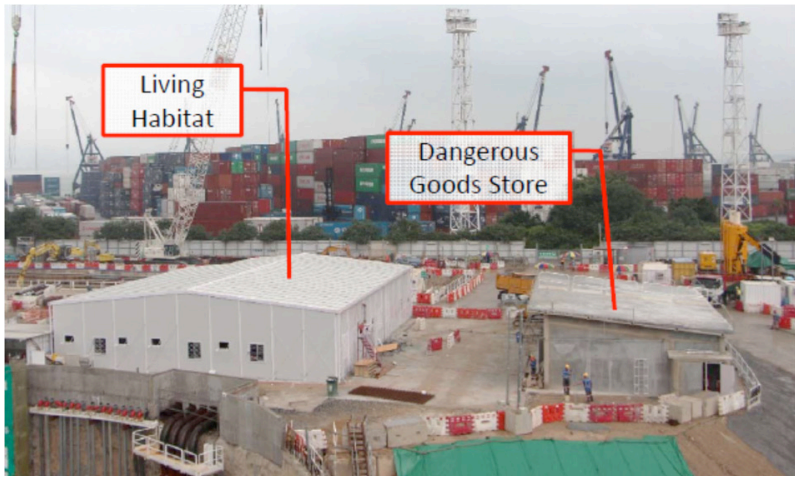

Figure 4. General view of Living Habitat and Dangerous Goods Store for trimix gas.

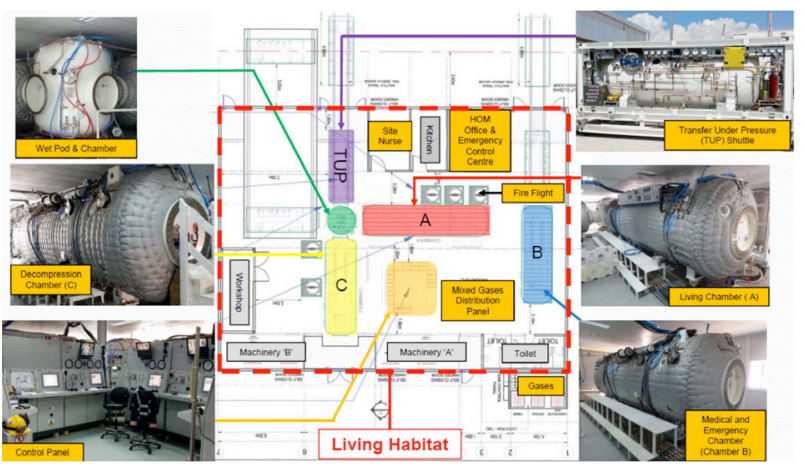

Figure 5. Layout of Living Habitat.

On the TBM, a built-in electrical winch and hoist system was designed to lift and handle the TUP shuttle carrying the saturation workers from the specialised vehicle to the TBM gantry platform and a scissor lift was equipped within the TBM to lift the TUP shuttle for connection to the TBM man lock by means of a special connection flange (Figure 6). The saturation workers were then able to work in the TBM excavation chamber for cutterhead interventions.

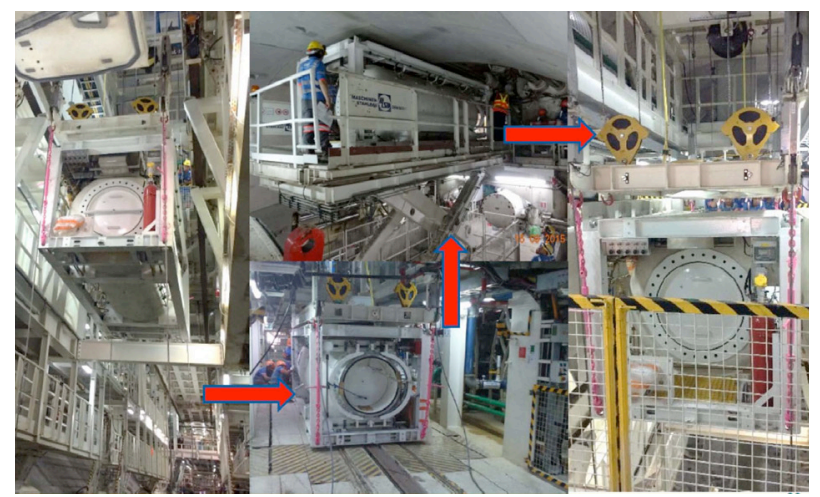

Figure 6. Provisions in the TBM for the saturation diving operation. 


\subsection{Medical Team for Saturation Diving Operation}

In the ITA guidelines, an AMP was required to take care of the health issues of the hyperbaric workers. In the IMCA guidelines, in a team of four saturation workers, two of them were required to be diving medics who were able to carry out first aid treatments in the event of any incident prior to treatments by the AMP.

The medical team for hyperbaric works in the TMCLKL project comprised an AMP from overseas, who had the medical experience of saturation diving works, as a consultant to oversee the health of the saturation workers of the project and supervise the local AMP.

The local AMP had to assist the overseas AMP to carry out daily health surveillance of the saturation workers while those workers were living in the hyperbaric environment and conduct medical checks of the saturation workers after they had finished the 3-day decompression at the end of the saturation cycle. Since there were occasions that the overseas AMP or local AMP was engaged or otherwise not available, a backup overseas AMP and a backup local AMP was required to take up the duties of the principal AMP.

A local trauma surgeon and a backup trauma surgeon were also appointed by the Contractor, who would be required to undertake surgical operations on the saturation workers in the event of incidents in the hyperbaric medical chamber under the hyperbaric environment.

As the diving medics were not legally authorised to carry out medical injections if needed during an incident, hyperbaric site nurses, working on shift, were employed who were able to work under hyperbaric environment, in the event of an emergency, to carry out nursing duties prior to the arrival of the local AMP.

\subsection{Saturation Diving Operation}

According to the IMCA guidelines, saturation workers were recommended to stay under hyperbaric environment for a cycle of 28 days including the decompression period. After completing the cycle, the saturation workers should take a rest of 28 days before beginning another saturation cycle. In addition, the same saturation workers were not recommended to work under pressure for more than 180 days within a year. Therefore, to carry out TBM cutterhead interventions for TM-CLKL project, a saturation diving team composed of over 50 staff members was employed which included 6 hyperbaric doctors, 3 nurses, 3 hyperbaric operation supervisors, 12 life support supervisors and technicians, and 30 saturation workers.

To start a saturation cycle, a team of four saturation workers were compressed and stored under pressure in the living chamber. When the two TBMs were excavating in the mixed ground where daily interventions to change the cutters were required, two teams of four saturation workers were required to be stationed in the living chamber.

Whenever an intervention was required for the TBM cutterhead, the team of four saturation workers would then go to the TUP shuttle, which would be carried by a specialised vehicle and travel from the living habitat all the way to the TBM (Figures 7 and 8). Upon arrival at the TBM, the tailored made TUP handling system on the TBM would lift the TUP shuttle and mount it to the manlock fitted with a flange to ensure air-tightness. The saturation workers would then go into the excavation chamber and start changing the worn-out cutters.

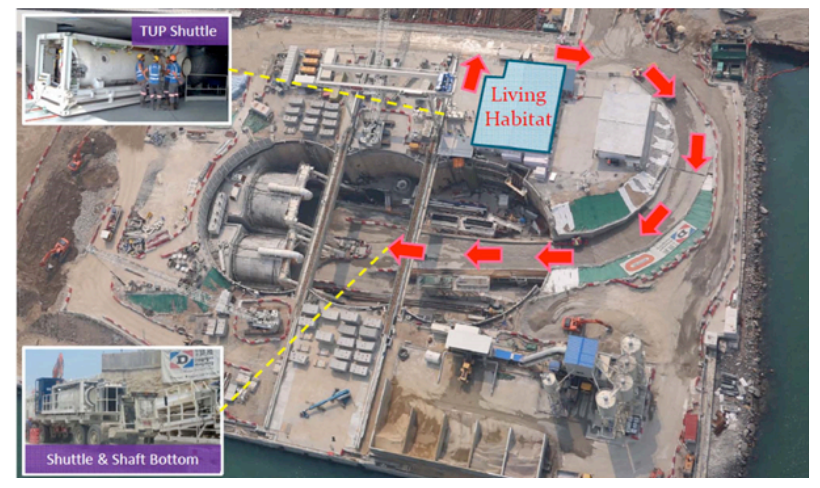

Figure 7. Transport of the TUP shuttle from the Living Habitat to the TBM.

(a)

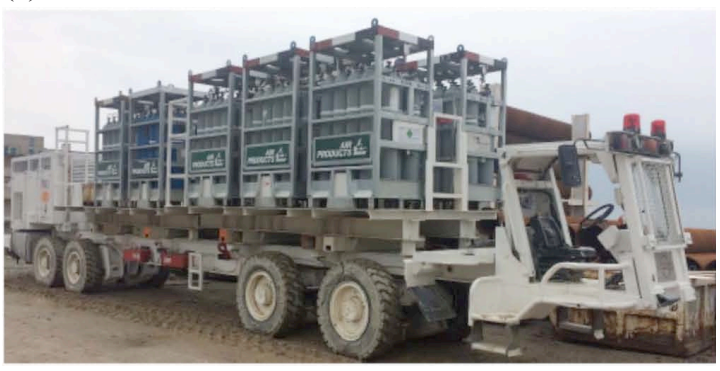

(b)

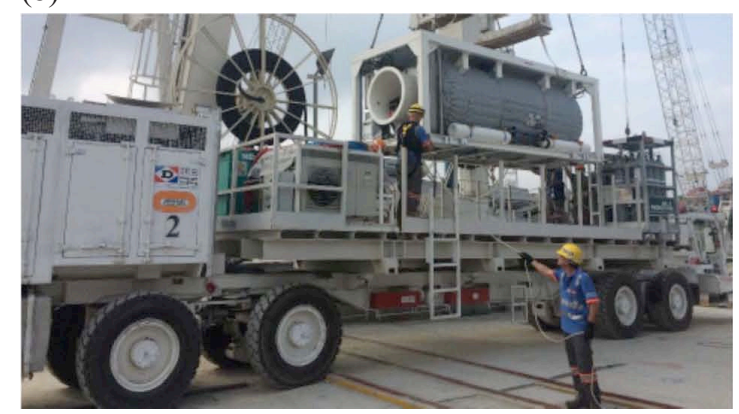

Figure 8. Special vehicles for trimix gas delivery and TUP shuttle delivery.

The allowable daily working time inside the TBM excavation chamber depended on the intervention pressure but in general was 6 hours a day. It was divided into two sessions with a 30-minute meal break inside the man lock.

After completing 6 hours' work, the saturation workers would return from the TBM excavation chamber to the TUP shuttle, which was again carried by the same 
specialised vehicle from the TBM back to the living habitat. The saturation workers would then take a shower in the Wet Pod and return to the living chamber to take a rest.

The team would stay in the living chamber for 25 days, with intervention works at the TBM whenever required. During the last 3 days, the saturation team would stay inside the decompression chamber to undertake the 3-day decompression cycle. When the decompression process was finished, the local AMP would conduct medical checkups, including Doppler monitoring to check the bubbles inside the body, before the team was allowed to leave the site.

\section{Achievements}

During the construction of the $5 \mathrm{~km}$-long TM-CLKL sub-sea tunnels, the air mode intervention was deployed at the approach tunnels at both the Northern Landfall and Southern Landfall for about $1 \mathrm{~km}$, whereas the trimix bounce inspection followed by the saturation intervention was deployed for about $4 \mathrm{~km}$ of the subsea tunnels. A total of 18 saturation cycles were conducted (Hydrokarst Group, 2019) for with more than 1,200-disc cutters changed for both TBMs and there was a zero case of decompression illness reported.

\section{Conclusion}

With no decompression illness reported during the whole period of sub-sea tunnelling works, the saturation diving technique was successfully implemented in the TM-CLKL project and it proved to be a safe technique for TBM interventions to minimise OSH risk for hyperbaric works. The experience gained in this project had therefore been incorporated into the updated version of the ITA Working Group No. 5 version 3 issued in March 2018 (The International Tunnelling Association Working Group, 2018).

\section{Acknowledgements}

The authors are grateful for the support from the Highways Department, Labour Department, Fire Services Department, Hong Kong Police Force of the HKSARG and the Hospital Authority. However, the content of this paper does not necessarily reflect the views and policies of these supporting organisations, nor does the mention of trade names and commercial products constitute endorsement or recommendations for use.

\section{Notes on Contributors}

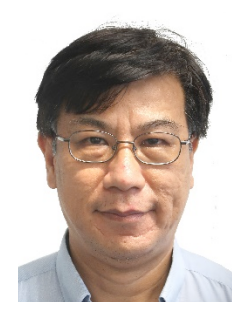

Ir Albert W Y Chan received his B.Sc. and M.Sc. degree in Civil Engineering from The University of Hong Kong in 1988 and 1996 respectively. He has more than 30 years of experience in delivering civil works projects in Hong Kong. For tunnel projects, he was involved in the Harbour Area Treatment Scheme Stage 1 and Stage 2A as well as the Tsuen Wan Drainage Tunnel project.

Albert is currently Chief Engineer of the East Development Office, Civil Engineering and Development Department. He was Senior Engineer in the Major Works Project Management Office (Special Duties) of the Highways Department managing the Tuen Mun-Chek Lap Kok Link project including the construction of the sub-sea tunnel until its completion.

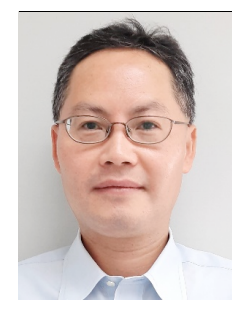

Ir Charles H C Yeung received his B.Sc. degree in Civil Engineering from The University of Hong Kong in 1988 and diplôme d'ingénieur from L'Ecole Nationale des Travaux Publics de l'Etat in France in 1990 respectively. He has more than 30 years of experience in tunnel projects involving drill and blast, and TBM. The tunnel projects he has been involved include Route 3 Tai Lam Tunnel, KCR West Rail Tai Lam Tunnel, KCR Lok Ma Chau Spur Line, MTR Kowloon Southern Link, MTR Express Rail Link, Tuen Mun-Chek Lap Kok Link Northern Connection Sub-sea Tunnel Section.

Charles is currently Senior Resident Engineer (Tunnel) in Hyder-Meinhardt JV supervising the Contract of Trunk Road T2 sub-sea tunnels. He was Senior Resident Engineer (TBM) in AECOM between 3 December 2013 and 31 December 2019 supervising the Contract of the Tuen MunChek Lap Kok Link Northern Connection Sub-sea Tunnel Section.

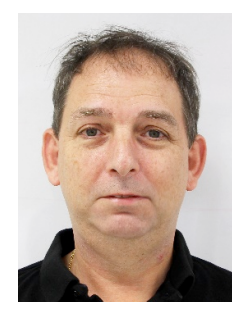

Ir Andy J. Westmoreland has more than 35 years of experience in the tunnelling industry, starting with the Singapore MRT in 1983, the Channel Tunnel Project in 1988 and the Storebaelt Project in Denmark in 1991 before settling in Hong Kong in 1995. In Hong Kong, he has been involved in a number of major tunnelling projects and the development of hyperbaric tunnelling. Andy was Chief Resident Engineer (TBM) for AECOM between 30 August 2013 and 31 December 2019 supervising the Contract of the Tuen Mun-Chek Lap Kok Link Northern Connection Sub-sea Tunnel Section and is currently in a similar role for Hyder- Meinhardt JV on the T2 Trunk Road Sub-Sea Tunnel Project. 


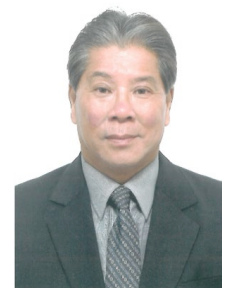

Ir S W Fok obtained his B.Sc. and BA degrees. He has 43-year solid construction experience in Hong Kong involving in an extremely wide range of both marine and land-based structures including bridges, viaducts, roads, drains, and hightech buildings. He also has extensive experience in TBM tunnelling, marine reclamation, site formation blasting and heavy foundations, i.e. bored piling, rock socket H-piles, diaphragm walling, top down construction and deep excavation for tunnelling and basement structures. He is Principal Resident Engineer of AECOM supervising the construction phase of the Tuen Mun-Chek Lap Kok Link project.

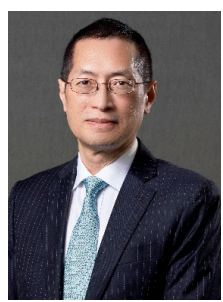

Ir Conrad C W Ng received his B.Sc. degree in Civil Engineering from The University of Hong Kong in 1982. He is currently Vice President of AECOM who has over 38 years of local experience in planning and feasibility study, design and documentation, project management, and construction and contract administration of various highway and tunnel infrastructure and major multi-disciplinary projects including Tseung Kwan O Tunnel, Route 8 between Cheung Sha Wan and Sha Tin, Central-Wan Chai Bypass and Island Eastern Corridor Link, Tuen Mun-Chek Lap Kok Link, Tseung Kwan O-Lam Tin Tunnel, Cross Bay Link, and Lok Ma Chau Loop.

Mr Fabrice Guedon was Project Director of DragagesBouygues Joint Venture, the Contractor for the Contract of the Tuen Mun-Chek Lap Kok Link Northern Connection Sub-sea Tunnel Section between 23 January 2017 and 10 July 2019.

\section{References}

[1] Hydrokarst Group (2019). Saturation works for maintenance operations in TBM - Hong Kong. [YouTube video] Available at: https://www.youtube. com/watch? $\mathrm{v}=$ cvAHuhFA3rA. [Accessed on 11 March 2021].

[2] Kindwall E P (1990) 'A short history of diving and diving medicine', in Bove, A. A. and Jefferson, C. D. (eds.) Diving medicine (2nd edn). WB Saunders Company, pp. 6-7.

[3] The Diving Medical Advisory Committee (2013). Accelerated emergency decompression (aed) from saturation DMAC 31.

[4] The Diving Medical Advisory Committee (2014). Medical equipment to be held at the site of an offshore diving operation, DMAC 15 Rev. 4.

[5] The Diving Medical Advisory Committee (2014). The provision of emergency medical care for divers in saturation, DMAC 28 Rev. 2.
[6] The Diving Medical Advisory Committee (2016). Saturation diving chamber hygiene, DMAC 26 Rev. 1.

[7] The International Marine Contractor Association (2014). Code of Practice for the initial and periodic examination, testing and certification of diving plant and equipment $\mathrm{D} 018$ Rev. 1.

[8] The International Tunnelling Association Working Group (2015). Guidelines for Good Working Practice in High Pressure Compressed Air, 5(2).

[9] The International Tunnelling Association Working Group (2018). Guidelines for Good Working Practice in High Pressure Compressed Air, 5(3). 